\title{
Interpreting Electroencephalogram (EEG) - An Introductory Review of Assessment and Measurement Procedures
}

\author{
Anubha Kalra ${ }^{1}$, Gautam Anand ${ }^{1} \&$ Andrew Lowe ${ }^{1}$ \\ ${ }^{1}$ Institute of Biomedical Technologies, Auckland University of Technology, Auckland, NZ \\ Correspondence: Anubha Kalra, Institute of Biomedical Technologies, Auckland University of Technology, \\ Auckland, NZ
}

Received: April 1, 2020

Accepted: May 11, 2020

Online Published: May 19, 2020

doi:10.5539/mas.v14n6p47

URL: https://doi.org/10.5539/mas.v14n6p47

\begin{abstract}
This work aims to compile various measurement and calibration techniques for Electroencephalogram (EEG). The objective is to provide an assessment of different components of an EEG and their significance in understanding different types of responses to stimuli. This review provides an overview of recommended electrode positions and lead systems for EEG with calibration and activation procedures. The different components of an EEG according to frequency bands - Gamma, Beta, Alpha, Theta and Delta have been discussed with emphasis on their interpretation and their role in several applications. The motivation behind this study is to provide a basic understanding of the composition of EEG, understanding the significance of each brain wave and the locations at which they are most prominent.
\end{abstract}

Keywords: Electroencephalogram, frequency bands, gamma, alpha, beta, theta, delta brain currents, brain wave mapping

\section{Introduction}

Hans Berger, a neuropsychiatrist from the University of Jena in Germany introduced the first Electroencephalogram (EEG) machine in year 1929. According to him, a change in the brain functions such as sleep, epilepsy caused a change in the brain currents. This led to the creation of a new branch of medical science called neurophysiology. A small number of disk electrodes were glued on the scalp and the signal received from the electrodes were amplified using operational amplifiers to observe the change in brain's activity. EEG monitoring is used to record the electrical activity or voltage fluctuations of the brain generated due to the ionic flow of current within the nerve cells. EEG finds its application in the diagnosis of epilepsy, brain tumours, stroke, sleep disorders, etc.

EEG is usually preferred for brain function assessment, along with several other neuroimaging techniques such as Magnetic Resonance Imaging (MRI) and Positron Emission Topography (PET), as it is the safest non-invasive technique and can be easily used for long-term bedside monitoring in intensive care units (Gasser and Molinari, 1996). Moreover, EEG has a higher time resolution (milliseconds) as compared to the PET or MRI (seconds to minutes). EEG analysis can be a time-series or a spectral assessment. Stimulated EEG responsesalso called as Evoked Potentials (EPs) are the time-series events which can be used for analysis of cognitive skills and psychophysiology and are based on the neuron excitation due to a visual or auditory response. EPs have a much smaller amplitude than EEG and cannot be differentiated from raw EEG, therefore, they are extracted by averaging the epochs of EEG, and contain significant patterns of the evoked neural activity (Teplan, 2002). Spontaneous EEG responses are analysed in frequency domain in terms of spectra and coherences. EEG is often affected by artefacts due to facial muscle activity (Electromyogram-EMG) or eye movement (Electrooculogram-EOG).

This paper describes an overview of the methods adopted for EEG assessment from various parts of the brain and the significance of brain waves of various frequencies. This review will first discuss the sensory positions, lead systems and calibration methods used for EEG assessment in clinical practice and then shift its focus on the brain oscillations, their significance and the locations they can be extracted from. 


\section{Background}

EEG arises from a cortical neural cell composed of $70-80 \%$ water and $20-30 \%$ protein and lipid, and can be classified on the basis of its structuring and functioning as (i) soma- cell body, (ii) dendrites- numerous short impulses of soma, (iii) axon- signal transporter or carrier from soma to another nerve or muscle cell (Malmivuo and Plonsey, 1995). The gap between the axon of one neural cell and the dendrites of another is called a synapse, and neurotransmitters also called as chemical messengers are responsible for the signal transportation across neurons (Maas, 1979).

A diagram depicting a cortical neuron which receives impulses from several thousand neurons is shown in figure 1 .

The bioelectricity generated due to the neural excitation can be measured on the scalp as EEG using wet or dry electrodes.

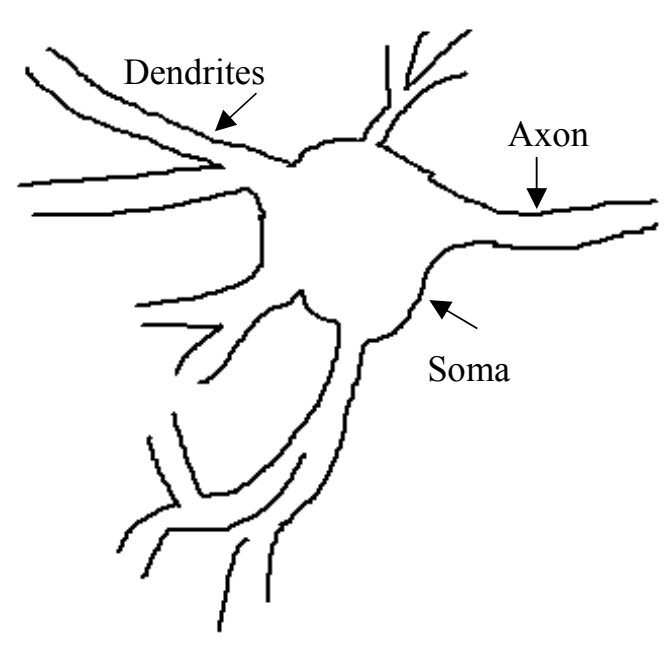

Figure 1. A cortical neuron with soma, dendrites and axon

EEG is measured as an electrical activity generated by similarly oriented groups of cortical neurons near the scalp where the electrodes are placed (Louis et al., 2016a). Action potentials are generated when neurons communicate with each other causing the membrane potential of soma to rise and fall rapidly. An action potential is only fired when a certain threshold voltage is reached and depends on the average of excitatory and inhibitory potentials. Action potentials are too short impulses to be measured and hence EEG is measured as a summation of excitatory and inhibitory postsynaptic potentials (Louis et al., 2016b).

\section{Electrode Positions and Lead Systems}

The 10-20 system is an internationally recommended method by the International Federation of Clinical Neurophysiology to describe the locations of twenty-one electrodes on the scalp. It is generally used to measure EEG from four main parts of the brain- frontal, central (top), temporal (sides) and occipital (back). The electrodes are equally interspaced according to skull size and shapes and are placed at $10 \%$ and $20 \%$ intervals from each other (Jasper, 1958; Tyner and Knott, 1983). Depending on type of application, the EEG can be extracted from 8 to 32 channels. EEG measurements can be bipolar or unipolar. The former refers to potential difference between a set of electrodes and the latter is the potential of each individual electrode with respect to reference electrode.

The Queen Square System (QSS) is preferred over the 10-20 system to measure Evoked Potentials (EPs) as the lateral occipital leads are placed farther from the centre, thereby allowing an improved recording of the scalp distribution of the patterned visual EPs (American Clinical Neurophysiology Society, 2006a). If electrodes are closer to each other, then the lead field current flows more and more within the skin than between the electrodes, thus decreasing the electrode sensitivity (Malmivuo and Plonsey, 1995). Both 10-20 system and QSS are depicted in figure 2. Reference points nasion on top of the nose and inion at the base of the skull are used as landmarks to place electrodes. 


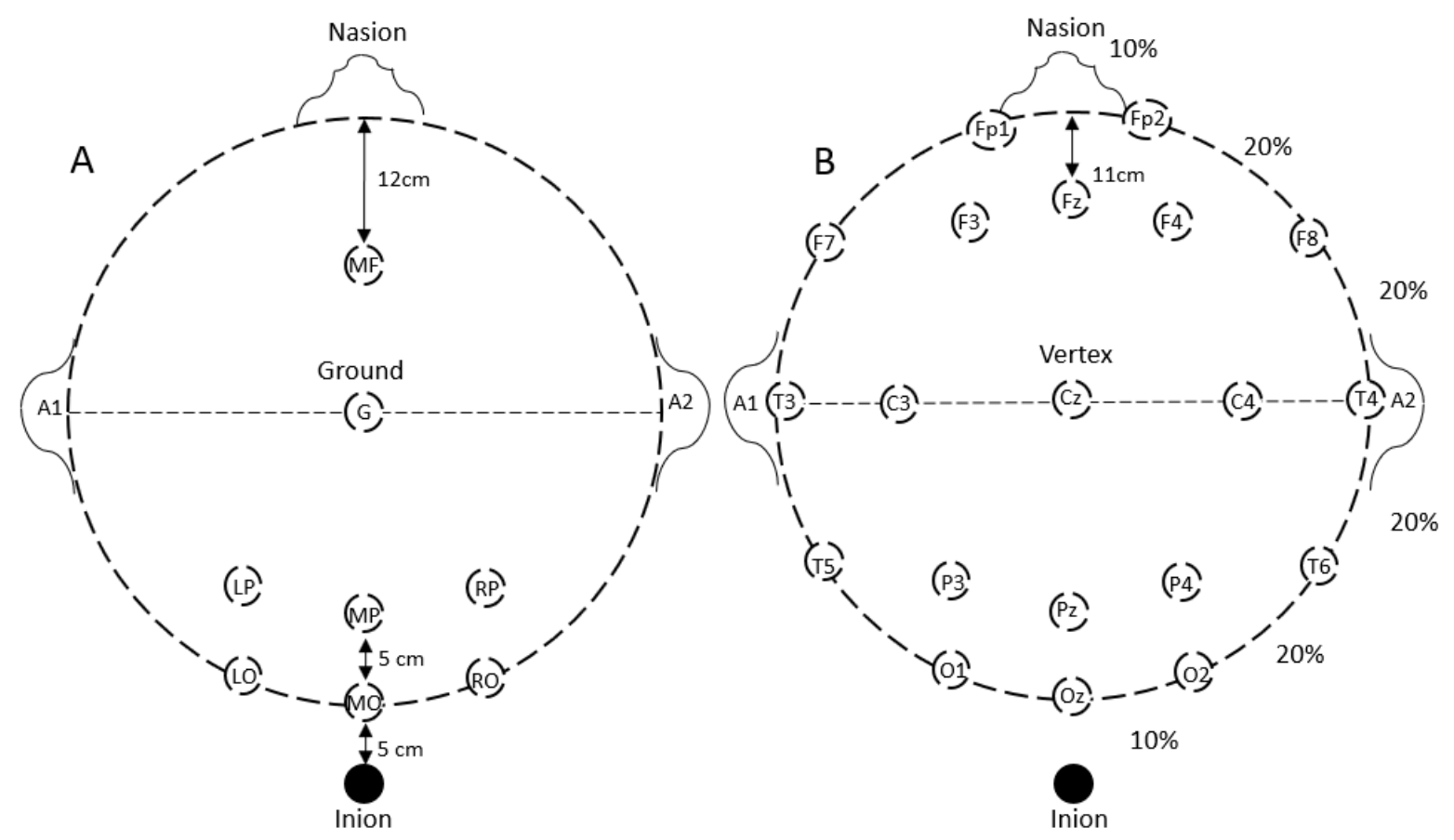

Figure 2. Difference between the Queen Square System (A) and the 10-20 system (B)

At least four channels should be recorded for the EPs employing QSS. In both 10-20 and QSS, even numbered and odd numbered electrodes refer to right and left side of the head respectively. G (in QSS) and $\mathrm{Cz} \& \mathrm{Fz}$ (in 10-20 system) are the ground electrodes, whereas A1 and A2 are used for contralateral referencing. A minimum of six EEG derivations are required using the 10-20 system to obtain activity from the frontal, central and the occipital regions. The recommended measurement channels for 10-20 system and QSS are F3-A2, C3- A2, O1-A2, F4- A1, C4-A2, O2-A1 and LO-MF, MO-MF, RO-MF, MF-A1 respectively ((American Clinical Neurophysiology Society, 2006a; Kushida et al., 2005)).

To measure EEG with higher density electrode settings, 10-10 and 10-5 systems employing more than 300 electrodes are also used ((“American Electroencephalographic Society guidelines for standard electrode position nomenclature," 1991; Jurcak et al., 2007)).

\section{EEG Measurement, Calibration and Activation Procedures}

According to 10-20 standard system, all twenty-one electrodes should be used for diagnostic EEG analysis, however, smaller number of electrodes are adequate for some specific analysis such as sleep study. The interelectrode impedances should not be more than 5000 Ohms (American Clinical Neurophysiology Society, 2006b). EEG are measured as peak to peak voltages and range from $0.5-100 \mu \mathrm{V}$.

According to the guidelines proposed by the American Clinical Neurophysiology Society, the minimum sampling frequency to acquire EEG signal should be three times the higher frequency filter setting to avoid aliasing (American Clinical Neurophysiology Society, 2006c). The low frequency filter setting higher than $1 \mathrm{~Hz}$ and the high frequency filter setting lower than $70 \mathrm{~Hz}$ is not recommended to obtain all brain waves. Due to low amplitudes of EEG waves, a 12-bit analog-to-digital conversion is recommended. A notch filter to reject the electromagnetic interference can be implemented. A grounding electrode should always be used except when other instruments are also attached to the patient, so as to avoid double grounding (American Clinical Neurophysiology Society, 2006b).

The effect of stimuli on the EEG should be recorded when the eyes are open and closed as some information is masked by the alpha activity and is only visible on the attenuation of alpha waves by opening eyes. Similarly, hyperventilation should be performed for a minimum of 3 minutes for adequate activation of EEG. The quality of hyperventilation, level of drowsiness and awareness in patients is also recorded by an electroencephalographer. Hyperventilation is performed to evoke elliptical abnormalities or seizures and to increase EEG sensitivity. The EEG should normally return back to its baseline level one minute after the conclusion of hyperventilation. If the 
return of EEG occurs after a protracted period, it may indicate an abnormality (Marcuse et al., 2016). For calibration purposes, it is the job of the technologist to assure that the patient is relaxed and maximally alert during certain epochs of assessment.

Intermittent Photo Stimulation (IPS) is also performed in EEG to detect photosensitivity (Kasteleijn-Nolst Trenité et al., 2012). IPS is performed by strobe light flashing between 1 to $35 \mathrm{~Hz}$ which evokes rhythmic waves in the occipital region of the brain. Lack of rhythmic waves do not indicate any abnormality, however, absence of waves on one side of the brain may indicate a unilateral structural disease involving the occipital region. This test is useful in patients with seizures where flickering light gives a photoparoxysmal response.

Sleep and sleep-deprived EEG are other standard tests that are used to detect unusual brain activity. Sleep EEG tests are generally conducted in children under five years of age to diagnose periods of epilepsy during sleep ((Arbasino et al., 2015; Kaminska et al., 2015; Kurahashi and Hirose, 1993; Weber et al., 2017; Werhahn, 2009)). On the contrary, sleep deprived tests are mostly conducted in adults where an increase in epileptiform activity is observed in about 30\% patients with epilepsy ((Marcuse et al., 2016; Renzel et al., 2016; Wirrell, 2010)). Epileptic events are also recorded during ambulatory monitoring, hospital and home video-telemetry ((Lawley et al., 2015; Seneviratne et al., 2013; Shafer et al., 2012)).

Other standard EEG tests involve the use of Neurofeedback systems which acquire the brain waves simultaneously and aid in self training to alter and improve the brain activity. These tests have shown huge improvements in children suffering from Attention Deficit Hyperactivity Disorder (ADHD) and in patients with eating disorders, anxiety and depression ((Alhambra et al., 1995; Arns et al., 2013; Boutros et al., 2005; Gordon et al., 2010; Laporte et al., 2002; Patrick, 1996; Snyder et al., 2008; Swartwood et al., 2003)).

\section{Brain Waves and What Do They Tell Us?}

As mentioned before, EEG or captured brain waves are an average of postsynaptic potentials and are generally sinusoidal in shape. EEG contains of several frequencies which are extracted by Fourier transform of raw EEG.

A person can be trained to generate more or less of these specific frequencies, which enables him/her to control his/her own brain function. A neurofeedback system is used for these purposes and is a popular technique applied in sports. It also provides solutions for attention training, stress, sleep, emotional difficulties and intimacy ((Albright, 2010; Fisher, 2014; Larsen, 2012; Robbins, 2008)).

Brainwaves can be divided into five general categories ranging from the highest frequency to lowest frequency content - Gamma, Beta, Alpha, Theta and Delta

\subsection{Gamma}

Gamma $(\gamma)$ waves are the fastest (or highest frequency $>32 \mathrm{~Hz}$ ) waves and are known to pass information rapidly. They were referred to as brain noise by some researchers until it was found to be dominant in states of higher virtues like meditation or altruism (Albright, 2010; Fisher, 2014; Larsen, 2012; Robbins, 2008). However, some studies have suggested that $\gamma$ waves are more likely a product of mismeasurement or constitutes of Electromyography (EMG) waves (Whitham et al., 2008, 2007; Yuval-Greenberg et al., 2008).

Gamma waves are known to originate in thalamus which lies at the top of the brain cell near the cerebral cortex (Herrero et al., 2002). The main purpose of thalamus is to relay motor and sensory signals. Low amounts of $\gamma$ waves are known to be linked to low memory and learning disabilities (Başar-Eroglu et al., 1996) and high amounts are linked with anxiety, high arousal and stress (Malik and Amin, 2017). Irregular $\gamma$ activity has been linked with Alzheimer's disease an epilepsy (Uhlhaas and Singer, 2006). Study conducted by Le Van Quyen M in 2016 (Quyen et al., 2016) suggests that $\gamma$ waves are highly correlated with the synchronous firing of inhibitory neurons.

Several studies have reported the emergence of stimuli-specific $\gamma$ waves between 30 to $80 \mathrm{~Hz}$ in the visual cortex located in the occipital lobe of anaesthetized cats and awake monkeys ((Brosch et al., 1997; Eckhorn et al., 1988; Engel et al., 1991; Freiwald et al., 1995; Frien et al., 1994; Gray et al., 1989; Kreiter and Singer, 1996)). Spike oscillations in the above studies were more frequent when the stimuli were visually coherent than random.

$\gamma$ waves have been classified into three classes in a study by as $40-\mathrm{Hz}$ transient evoked response, $40-\mathrm{Hz}$ steady state response and induced gamma $(30-80 \mathrm{~Hz})$ response (Tallon-Baudry and Bertrand, 1999). Evoked $\gamma$ responses occur on the onset of an external stimuli- audio, visual or physical and has the same latency and phase in each trial. Thus, it can be analysed as an average of several trials. The evoked response is known to disappear during sleep and Rapid Eye Movement sleep (REM) (Llinás and Ribary, 1993). Steady state responses at 40-Hz are interpreted in terms of natural resonant frequencies of brain (Galambos et al., 1981) (42). In another study 
(Regan and Spekreijse, 1986), periodic EPs like light flashes generated steady state $\gamma$ response in mid frequency range $-40 \mathrm{~Hz}$ when measured from $\mathrm{Pz}$ and $\mathrm{Oz}$. The response was measured from the occipital area and was found dependent on luminance and not colour at $40 \mathrm{~Hz}$ and both luminance and colour below $40 \mathrm{~Hz}$. Steady state EPs are better analysed in frequency than averaging in time. The induced gamma responses are oscillatory bursts and their latency differs from trial to trial (see figure 3).

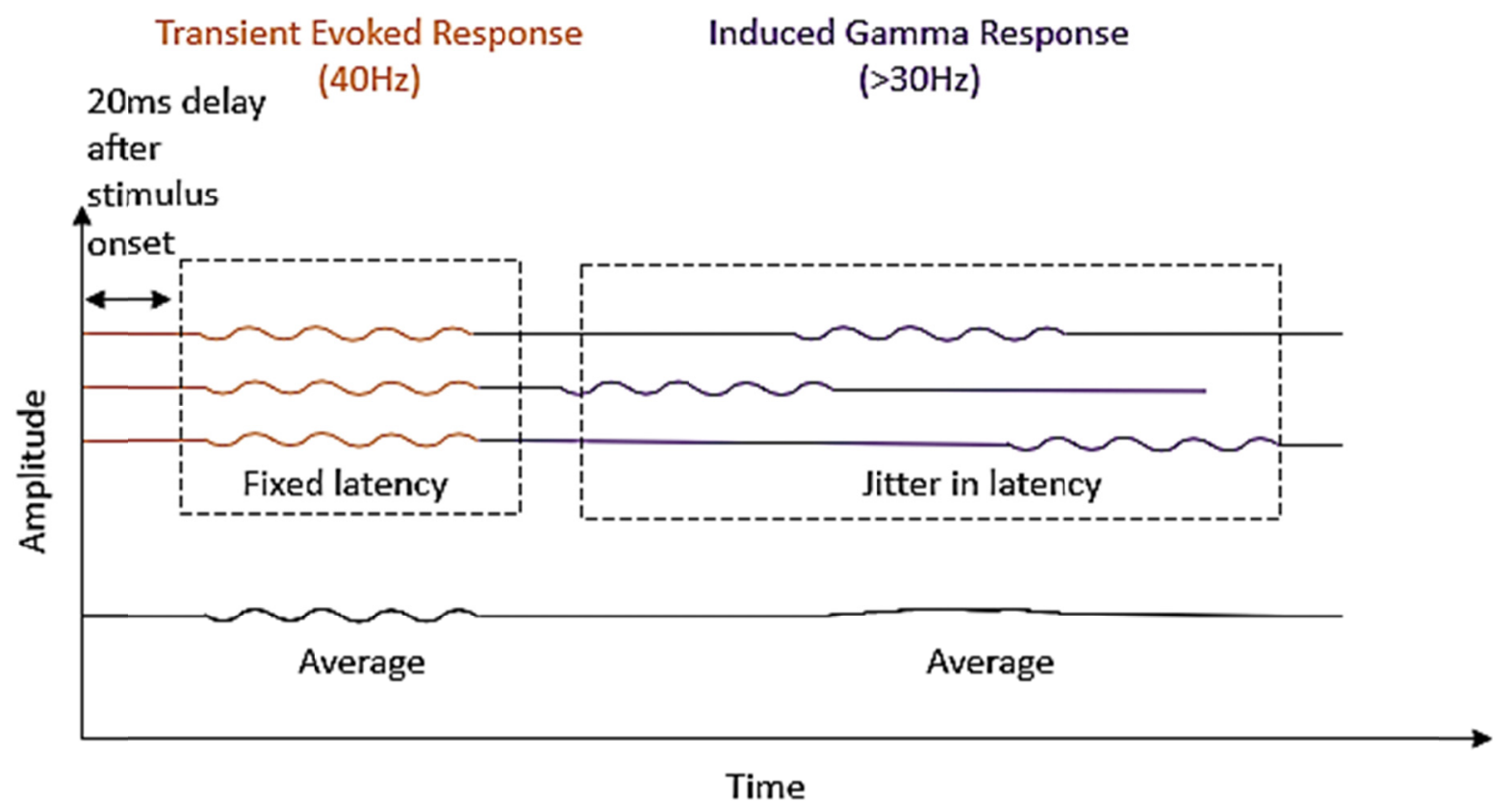

Figure 3. Difference between transient evoked and induced gamma response

A simple method to evaluate Gamma Band Activity (from 30 to 90Hz) was carried out by Amo et al, 2016 (Amo et al., 2016). The study was conducted using the standard 10-20 system where only three EEG channels (C3, C4 and $\mathrm{Cz}$ ) were recorded and only one channel $(\mathrm{Cz})$ was used for data analysis due to its less susceptibility to EMG artefacts. The subjects were advised to keep their eyes open and their gaze fixed on the centre of the computer screen for the first part of the study $\left(\gamma_{\text {Basal }}\right)$, while the second part involved execution of a motor action on receiving an on-screen cue $\left(\gamma_{\text {movement }}\right)$. The gamma activity was observed to increase during movement and motor area activity parameter index $\mathrm{I}_{\gamma}$ was calculated as in equation 1.

$$
\mathrm{I}_{\gamma}=\gamma_{\text {movement }} / \gamma_{\text {basal }}
$$

Experiments conducted by Fitzgibbon et al. in 2012 (Fitzgibbon et al., 2013) also supported that EEG recorded from the central scalp muscle $(\mathrm{Cz})$ are least contaminated by EMG and Electrooculography (EOG) artefacts including jaw clenching and eye blinking. Gamma activity generated due to index finger abduction, bicep contraction and foot movement were mostly observed in central parts of the brain in a study by Cheyne et. al., 2008 (Cheyne et al., 2008), as seen in figure 4. The motor stimulated gamma band was found to be more dominant in the visual cortex of the brain in several studies employing Magnetoencephalography (MEG) (Adjamian et al., 2004; Hadjipapas et al., 2007; Muthukumaraswamy and Singh, 2008; Quyen et al., 2016; Swettenham et al., 2009). 


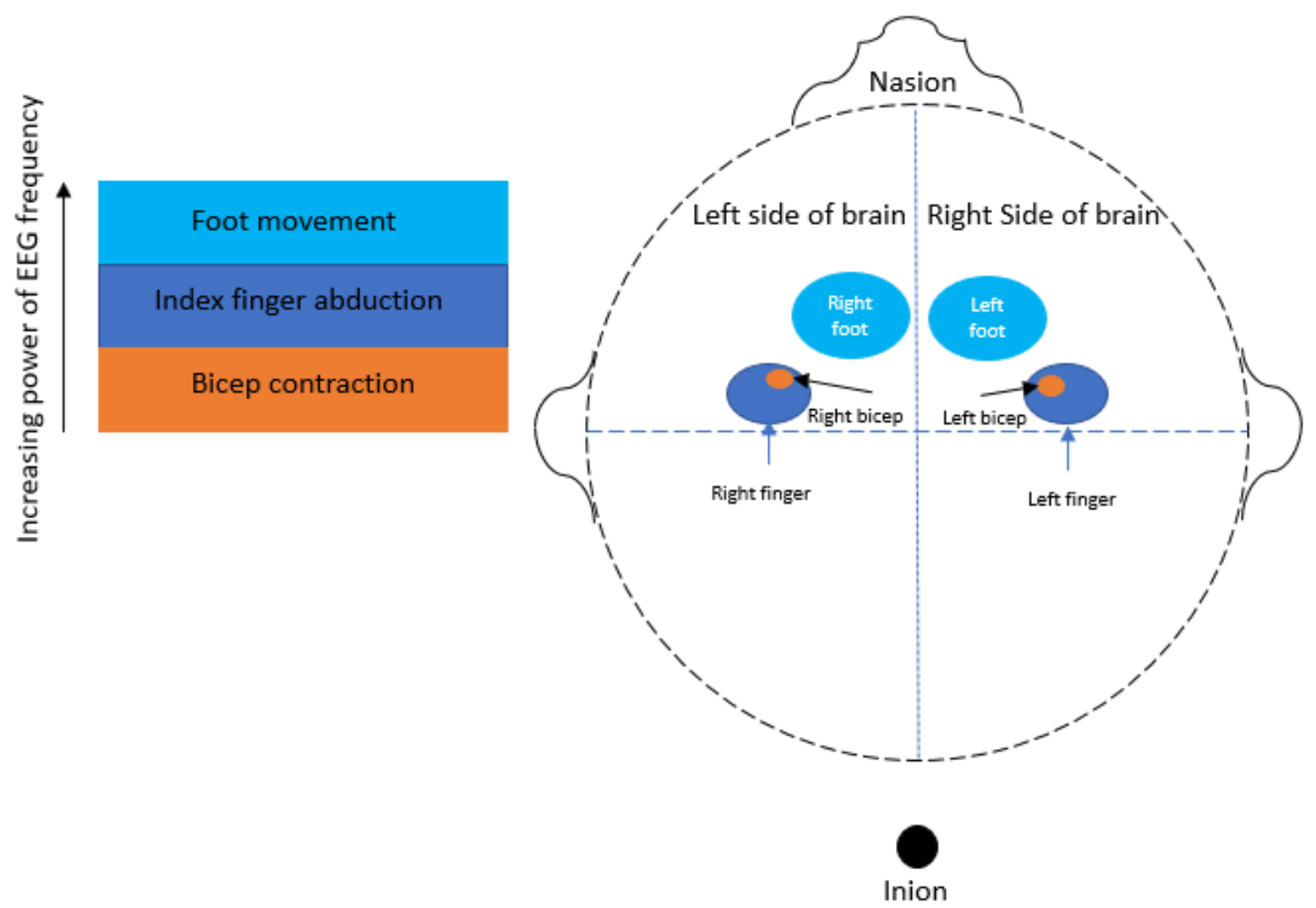

Figure 4. Gamma activity related to motor cortex

\subsection{Beta}

Beta $(\beta)$ waves lie between $12-38 \mathrm{~Hz}$ and are found in various locations of the cortex. Beta waves are classified on basis of their frequency bands as (a) lo beta or Beta $1(12-15 \mathrm{~Hz})$, (b) Beta or Beta $2(15-22 \mathrm{~Hz})$, and (c) hi beta or Beta $3(22-38 \mathrm{~Hz})(14)$.

Lo beta is associated with focuses, introvert concentration, Beta 2 with high energy, anxiety and performance, and hi beta with stress, anxiety and high arousal (Abhang et al., 2016).

$\beta$ rhythms are also classified as Rolandic and frontal based on the locations they are extracted from (Kropotov, 2009). The former is found in central (C3, Cz and C4) part of the brain and the latter in frontal (F3, F4).

Rolandic or Mu wave (8-13Hz) is considered as a subharmonic of $\beta$ activity (Hobson and Bishop, 2017) and was first described by Gestalt et al. ((Hf Gastaut, 1952; H. Gastaut, 1952)). Mu waves appear like pyramidal, arch shape waves which are suppressed on movement, thinking of movement and on watching others move as a sign of neuron mirroring. Mu waves are mainly highlighted in the central regions of the brain $(\mathrm{C} 3, \mathrm{C} 4)$ and are most active when a person is at rest or in state of drowsiness with eyes open (Amzica and Silva, n.d.). Mu waves are generally studied in people with Autism Spectrum disorder (ASD). Autism is considered to be influenced by an altered mirror neural system and is viewed as disordered understanding of other people's intentions ((Bernier et al., 2007; Oberman et al., 2005; Williams et al., 2006)). In a study performed on 20 people (10 ASDs and 10 typically developed TDs) within the age group 6-47 years, ASDs showed a supersession of mu wave during own movement as opposed to TDs where mu waves were suppressed during own movement as well as while observing others move (Oberman et al., 2005). However, in another study (19ASDs and 19TDs) conducted on 6-year olds, mu suppression was found on both groups (Bernier et al., 2013).

Rolandic EEG waves are present in both alpha and beta frequencies and exhibit different dynamics in both ranges. Rolandic waves are more active in a 'resting state' (Ritter et al., 2009), while, frontal $\beta$ rhythms are visible in performing cognitive tasks which are stimuli initiated or related to decision making. Both Rolandic and frontal $\beta$ rhythms can be present at the same time. In trials including motor-related movement (lifting finger), Rolandic waves were suppressed during the preparation for movement, and were not suppressed when no preparation to make a movement was involved (Kropotov, 2009). Rolandic waves are also observed after an activity is performed when the neural system in the sensory motor strip is relaxing. 
Rolandic $\beta$ rhythms are extremely useful to study the basal ganglia - one of the most crucial areas of the brain including drug addiction, learning and memory and psychopathology ((Aron et al., 2009; Nambu, 2009; Packard, 2001; Watkins and Jenkinson, 2016)). However, $\beta$ waves (of high amplitudes) are mostly picked up from the front side of the brain and their absence may indicate cortical damage (EEG Brain Signal Classification for Epileptic Seizure Disorder Detection, 2019).

The amplitude of frontal $\beta$ activity (within 14-16 Hz) is increased during drowsiness or due to sedative drugs (Marcuse et al., 2016). Low amplitude and higher frequency $\beta$ waves (hi Beta) on other hand are associated with active, busy or anxious thinking or traumatic brain injury (Buzsaki, 2006).

In one of the studies (Baker, 2007), the muscle cortex $\beta$ activity was found to be suppressed during motion and preparation of motion. Several studies have shown high correlation of $\beta$ waves in maintenance of cortical state for steady motor output (Androulidakis et al., 2007, 2006; Gilbertson et al., 2005; Kristeva et al., 2007). $\beta$ activity due to oscillatory activity is elevated in motor disorders such as Parkinson's disease (McAllister et al., 2013).

Several studies also suggest the role of $\beta$ waves in strengthening and recalibrating the sensorimotor feedback, whereas $\beta$ waves are reduced during a change in motion or instructions. A reduction in $\beta$ activity is observed when the motion is resisted ((Lalo et al., 2007; Zhang et al., 2008)). $\beta$ activity can be useful in analysing interhemispheric asymmetry. A focal decrease or increase in $\beta$ waves can relate to brain abscess, stroke, tumours, vascular malformations and cortical dysplasia (Marcuse et al., 2016).

\subsection{Alpha}

Alpha waves $(\alpha)(8-13 \mathrm{~Hz})$ (Foster et al., 2017) were first recorded EEG by the Berlin psychiatrist Hans Berger in 1929 from the occipital region of the brain (Karbowski, 2002). They aid in mental coordination and calmness and represent a relaxed state of mind where a person is a rest and not asleep. In human beings, $\alpha$ waves start appearing at four months and matures at 3 years of age (Niedermeyer, 1997). They are predominant when the eyes are closed and attenuated by eye opening and are also measured from the frontal-central region of the brain during REM (Rapid Eye Movement) sleep marked by intense brain activity. Alpha activity in the occipital lobe has been reported to be linked with the inhibition of planned actions and with momentary memory storage in the frontal lobe (Baars and Gage, 2013). Desynchronization (or suppression) of $\alpha$ rhythm due to a corresponding sensory input and synchronisation (marked by an increase in amplitude) due to inhibition of sensory input play a role in cognitive processes of the brain (Quantitative EEG, Event-Related Potentials and Neurotherapy, 2009). In one of the studies, frequencies of $\alpha$ rhythm were found to decrease with age from 7 to 80 years (Kropotov, 2016). However, the variations are relatively small and $\alpha$ rhythms below $7.5 \mathrm{~Hz}$ should be considered abnormal. Alpha waves can be slightly asymmetric between the left and right hemispheres of the brain. However, a persistent asymmetry of more than $2 \mathrm{~Hz}$ is regarded as abnormal. The side with a lower frequency is generally the abnormal one (Aminoff, 2012).

Alpha waves can be classified as $\alpha 1$ (below $8 \mathrm{~Hz}), \alpha 2(8-10 \mathrm{~Hz}), \alpha 3(10-13 \mathrm{hz})$. Some recent studies have demonstrated that an increase in the $\alpha 3 / \alpha 2$ ratio is a marker of mild cognitive impairment representing the "at-risk" state of developing dementia ((Moretti et al., 2013, 2012, 2011)). In another study EEG obtained from 1340 healthy children between 3-12 years indicated that $\alpha 1$ reduces and $\alpha 2$ increases with age, while no change in $\alpha 3$ was observed (Ogawa et al., 1989). The development of the $\alpha$ activity was also found to develop faster in the occipital than the central regions of the brain. Peak alpha frequency during resting state and photo stimulated evoked response was found to reduce in patients with first episode psychosis (FEP) as compared to healthy control groups in a recent study by Murphy et al (Murphy and Öngür, 2019).

In another study where $\alpha$ waves were evoked using a visual-semantic categorization task, it was indicated that the speed of $\alpha$ waves from midline occipital to right parietal sites was inversely related to the reaction time or the fast picture categorization (Fellinger et al., 2012).

\subsection{Theta}

Theta waves are slow waves lying within the frequency range of 4 to $8 \mathrm{~Hz}$ that are present in waking adults and may be completely absent in some people (Marcuse et al., 2016). Theta $(\theta)$ rhythm is found in around $35 \%$ of young adults in the frontocentral region of the brain. Absence of $\theta$ on one side of the brain may indicate an underlying cause of structural disease.

Brain's memory system can be found in three parts of the brain viz. Hippocampus, cortex and striatum (Headley and Paré, 2017). Theta waves have been linked to memory formation and navigation ((Lega et al., 2012; Tesche 
and Karhu, 2000)), and are the strongest in Hippocampus during movement, REM sleep and sniffing (Vanderwolf, 1969).

Some studies have suggested a stronger presence of $\theta$ waves during hypnosis or no thought meditation in humans (Aftanas and Golocheikine, 2001). Several studies have indicated relation of theta waves recorded from the frontal midline region with attention processes, memory and arithmetic tasks ((Gevins et al., 1997; Grunwald et al., 1999; Ishihara and Yoshii, 1972; McEvoy et al., 2001; Sasaki et al., 1996; Smith et al., 1999; Tsujimoto et al., 2006)). Presence of higher frontal $\theta$ is more observed in people who are less anxious or neurotic and more extrovert (Mizuki et al., 1984). Higher $\theta$ waves can be an indication of improvement in treating patients with depression (Pizzagalli et al., 2001).

Theta waves are a tag for short term memory processing that can either appear due to voluntary (locomotion and REM sleep) or involuntary (sedative state) actions and are termed as Type I and Type II theta respectively (Kramis et al., 1975). Active movements such as running, jumping and exploration in rats was found to be highly associated with $\theta$, where higher $\theta$ was found on running faster. During exploration a rat continually gathers and updates information which is stored temporarily in hippocampus. If the exploration bears rewards (or punishments), the inputs to the hippocampus are modulated and the short-term theta memories are converted into long-term memories (Vertes, 2005).

\subsection{Delta}

Delta waves (also known as Zeta waves) are the high amplitude, low frequency $(>4 \mathrm{~Hz})$, saw tooth shaped waves which were discovered by W.Gray Walter in 1936 (Magnus and Van der Holst, 1987). Delta waves $(\Delta)$ are found in cases of NREM (Non-REM) or deep sleep and their presence in the state of wakefulness indicates cerebral dysfunction. They form an important part of sleep in adults, are more commonly found in the occipital region of babies and are found to reduce during adolescence (Marcuse et al., 2016). Sleep walking and talking occur during high $\Delta$ activity (Pilon et al., 2006).

Sleep can be classified in four stages-I to IV. During the initial sleep stage, $\beta$ waves can be observed which eventually diminish and lead to the visibility of $\alpha$ rhythm. Stage I embarks theta activity in which people are still somewhat awake and alert. Ten minutes after stage I marks the beginning of sleep spindles (Stage II) for around 20 minutes. Delta waves can be seen in stage III when people are less responsive and aware of their external environment. In stage III, half of the brain consists of $\Delta$ waves as compared to stage IV where more than half of the brain produces these waves. The sleep stage IV aids in healing and regeneration and is followed by REM stage where the brain begins to dream ((Colrain et al., 2009; Sekimoto et al., 2011)). Stage IV sleep and $\Delta$ waves can be entirely absent by the age of 75 years (Colrain et al., 2010).

Delta waves are preceded by K complex which are the largest event in a healthy human EEG (Cash et al., 2009). $\mathrm{K}$ complex can be seen as high amplitude $(>100 \mathrm{uV})$ peak (see figure 5$)$ which occurs during sleep stage II. K complex are known to protect sleep by supressing cortical arousal and engage in information processing and memory consolidation (Tononi and Cirelli, 2006).

Research studies have shown that $\Delta$ waves are more prominently found in females than males (Ehlers and Kupfer, 1997). Delta waves can be obtained from frontal, temporal and occipital lobes where each location holds significance in terms of diagnosing pathological disorders. Some studies ((Accolla et al., 2011; Watemberg et al., 2002)) suggest that $\Delta$ activity found in frontal region during wakefulness may indicate metabolic impairment (renal failure or hyperglycaemia) and brain lesions. Polymorphic $\Delta$ activity marked by sharp spikes in temporal regions of the brain is usually a sign of Type II diabetes ((Abdelkarim et al., 2002; Dijk, 2008)) brain injury (Inui et al., 1994) and temporal lobe epilepsy (Walter, 1936), whereas in occipital regions it can indicate absence seizures (Brigo, 2011). 
Sleep Stage II

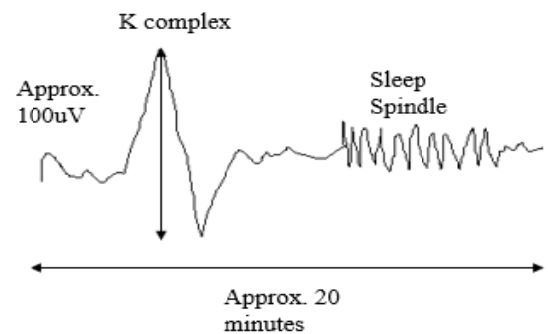

Figure 5. Formation of K complex before the start of $\Delta$ activity

Both theta and delta waves originating in hippocampus and cortex respectively are known to modulate gamma waves (Headley and Paré, 2017) which occur throughout cortex, hippocampus and striatum during waking and sleep.

\section{Conclusion}

EEG measurement and assessment has always been a difficult area due to ambiguity in the obtained waveform because of the presence of small amplitude multitone signals. The locations of the electrodes and the skin-electrode impedance play a very important role in EEG interpretation as they can be easily corrupted by noise. This paper provides a detailed description of EEG activation and calibration methods and gives a good understanding of the associated brain waves.

A brief summary of the above findings can be seen in figure 6 .

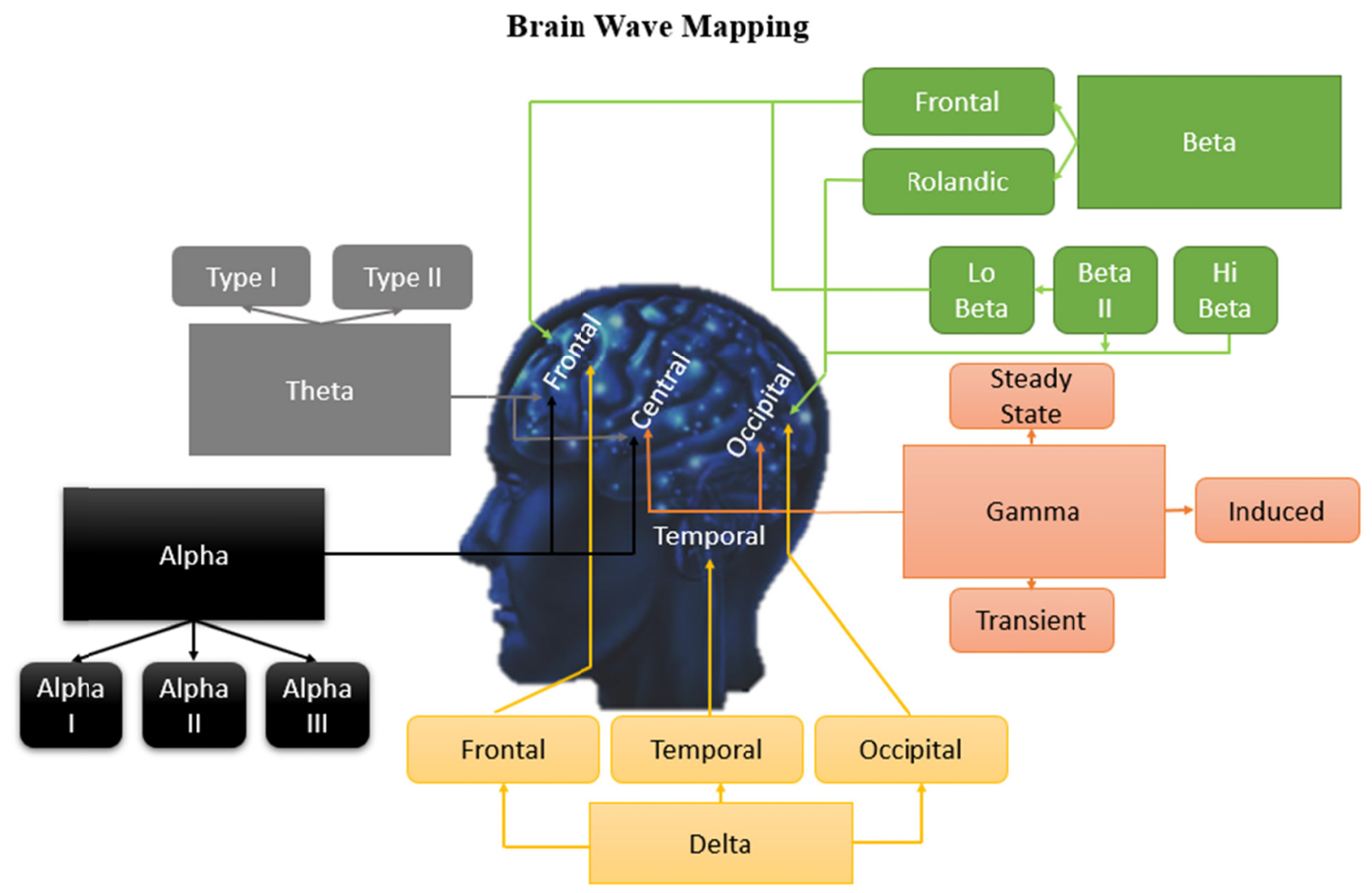

Figure 6. Origination and classification mapping of brain waves 


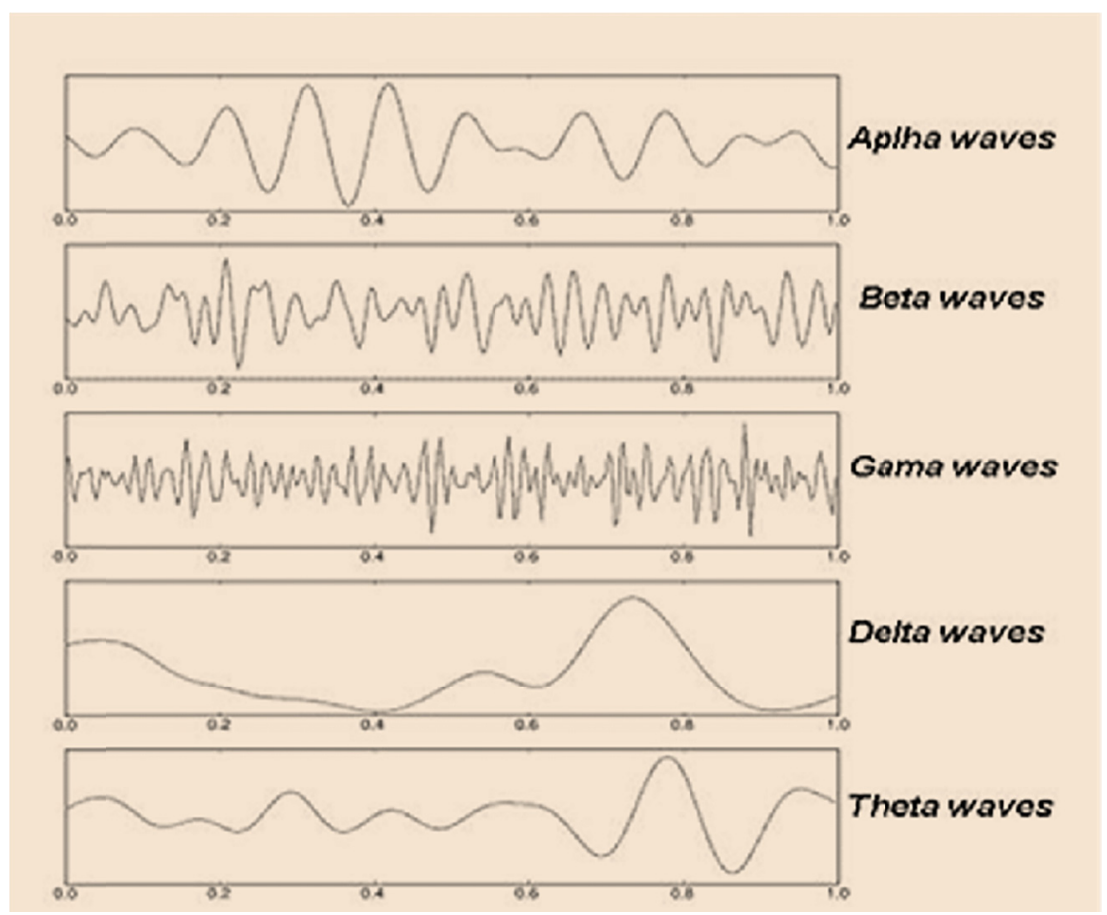

Figure 7. A diagrammatic representation of brain waves- Alpha, Beta, Gama, Delta and Theta

\section{References}

Abdelkarim, T.H., Westin, T., Romaker, A. \& Girish, M. (2002). Presence of delta waves in REM sleep during polysomnography as a sign of acute hypoglycemic encephalopathy. SLEEP. AMER ACAD SLEEP MEDICINE 6301 BANDEL RD, STE 101, ROCHESTER, MN 55901 USA, A380-A380.

Abhang, P.A., Gawali, B.W. \& Mehrotra, S.C. (2016). Chapter 3 - Technical Aspects of Brain Rhythms and Speech Parameters, Abhang, P.A., Gawali, B.W., Mehrotra, S.C. (Eds.). Introduction to EEG- and Speech-Based Emotion Recognition. Academic $\quad$ Press, https://doi.org/10.1016/B978-0-12-804490-2.00003-8

Accolla, E.A., Kaplan, P.W., Maeder-Ingvar, M., Jukopila, S. \& Rossetti, A.O. (2011). Clinical correlates of frontal intermittent rhythmic delta activity (FIRDA). Clin. Neurophysiol. off. J. Int. Fed. Clin. Neurophysiol, 122, 27-31. https://doi.org/10.1016/j.clinph.2010.06.005

Adjamian, P., Holliday, I.E., Barnes, G.R., Hillebrand, A., Hadjipapas, A. \& Singh, K.D. (2004). Induced visual illusions and gamma oscillations in human primary visual cortex. Eur. J. Neurosci, 20, 587-592.

Aftanas, L.I. \& Golocheikine, S.A. (2001). Human anterior and frontal midline theta and lower alpha reflect emotionally positive state and internalized attention: high-resolution EEG investigation of meditation. Neurosci. Lett, 310, 57-60. https://doi.org/10.1016/s0304-3940(01)02094-8

Albright, C. (2010). Neurofeedback: Transforming Your Life with Brain Biofeedback. Beckworth Publications, Trenton, MO.

Alhambra, M.A., Fowler, T.P. \& Alhambra, A.A. (1995). EEG biofeedback: A new treatment option for ADD/ADHD. J. Neurother, 1, 39-43.

American Clinical Neurophysiology Society. (2006a). Guideline 9B: Guidelines on visual evoked potentials. $J$. Clin. Neurophysiol. Off. Publ. Am. Electroencephalogr. Soc, 23, 138-156.

American Clinical Neurophysiology Society. (2006b). Guideline 1: Minimum technical requirements for performing clinical electroencephalography. J. Clin. Neurophysiol. Off. Publ. Am. Electroencephalogr. Soc, 23, 86-91.

American Clinical Neurophysiology Society. (2006c). Guideline 8: Guidelines for recording clinical EEG on digital media. J. Clin. Neurophysiol. Off. Publ. Am. Electroencephalogr. Soc, 23, 122-124. 
American Electroencephalographic Society guidelines for standard electrode position nomenclature. (1991). J. Clin. Neurophysiol. Off. Publ. Am. Electroencephalogr. Soc, 8, 200-202.

Aminoff, M.J. (2012). Chapter 3 - Electroencephalography: General Principles and Clinical Applications, Aminoff, M.J. (Ed.). Aminoff's Electrodiagnosis in Clinical Neurology (Sixth Edition). W.B. Saunders, London, 37-84. https://doi.org/10.1016/B978-1-4557-0308-1.00003-0

Amo, C., Castillo, M.O. del, Barea, R., Santiago, L. de, Martínez-Arribas, A., Amo-López, P. \& Boquete, L. (2016). Induced Gamma-Band Activity During Voluntary Movement: EEG Analysis for Clinical Purposes. Motor Control, 20, 409-428. https://doi.org/10.1123/mc.2015-0010

Amzica, F., Silva, F.H.L. da, n.d. Cellular Substrates of Brain Rhythms. Oxford University Press.

Androulidakis, A.G., Doyle, L.M.F., Gilbertson, T.P. \& Brown, P. (2006). Corrective movements in response to displacements in visual feedback are more effective during periods of $13-35 \mathrm{~Hz}$ oscillatory synchrony in the human corticospinal system. Eur. J. Neurosci, 24, 3299-3304. https://doi.org/10.1111/j.1460-9568.2006.05201.x

Androulidakis, A.G., Doyle, L.M.F., Yarrow, K., Litvak, V., Gilbertson, T.P. \& Brown, P. (2007). Anticipatory changes in beta synchrony in the human corticospinal system and associated improvements in task performance. Eur. J. Neurosci, 25, 3758-3765. https://doi.org/10.1111/j.1460-9568.2007.05620.x

Arbasino, C., Calorio, F., d'Orsi, G., Marchioni, E., Tartara, E., Marchese, D., Rustioni, V., Moglia, A. \& Galimberti, C.A. (2015). Interictal spiking in adult newly-diagnosed focal epilepsy of unknown cause: The effect of age. Clin. Neurophysiol. Off. J. Int. Fed. Clin. Neurophysiol, 126, 1498-1504. https://doi.org/10.1016/j.clinph.2014.10.155

Arns, M., Conners, C.K. \& Kraemer, H.C. (2013). A decade of EEG theta/beta ratio research in ADHD: a meta-analysis. J. Atten. Disord, 17, 374-383.

Aron, A.R., Poldrack, R.A. \& Wise, S.P. (2009). Cognition: Basal Ganglia Role, Squire, L.R. (Ed.). Encyclopedia of Neuroscience. Academic Press, Oxford, 1069-1077. https://doi.org/10.1016/B978-008045046-9.00410-1

Baars, B.J. \& Gage, N.M. (2013). Chapter 8 - The brain is conscious, Fundamentals of Cognitive Neuroscience. Academic Press, San Diego, 211-252. https://doi.org/10.1016/B978-0-12-415805-4.00008-4

Baker, S.N. (2007). Oscillatory interactions between sensorimotor cortex and the periphery. Curr. Opin. Neurobiol., Motor systems / Neurobiology of behaviour, 17, 649-655. https://doi.org/10.1016/j.conb.2008.01.007

Başar-Eroglu, C., Strüber, D., Schürmann, M., Stadler, M. \& Başar, E. (1996). Gamma-band responses in the braa short review of psychophysiological correlates and functional significance. Int. J. Psychophysiol., New Advances in EEG and cognition, 24, 101-112. https://doi.org/10.1016/S0167-8760(96)00051-7

Bernier, R., Aaronson, B. \& McPartland, J. (2013). The role of imitation in the observed heterogeneity in EEG $\mathrm{mu}$ rhythm in autism and typical development. Brain Cogn, 82, 69-75. https://doi.org/10.1016/j.bandc.2013.02.008

Bernier, R., Dawson, G., Webb, S. \& Murias, M. (2007). EEG mu rhythm and imitation impairments in individuals with autism spectrum disorder. Brain Cogn, 64, 228-237. https://doi.org/10.1016/j.bandc.2007.03.004

Boutros, N., Fraenkel, L. \& Feingold, A. (2005). A four-step approach for developing diagnostic tests in psychiatry: EEG in ADHD as a test case. J. Neuropsychiatry Clin. Neurosci, 17, 455-464.

Brigo, F. (2011). Intermittent rhythmic delta activity patterns. Epilepsy Behav, 20, 254-256. https://doi.org/10.1016/j.yebeh.2010.11.009

Brosch, M., Bauer, R. \& Eckhorn, R. (1997). Stimulus-dependent modulations of correlated high-frequency oscillations in cat visual cortex. Cereb. Cortex, 7, 70-76. https://doi.org/10.1093/cercor/7.1.70

Buzsaki, G. (2006). Rhythms of the Brain. Oxford University Press.

Cash, S.S., Halgren, E., Dehghani, N., Rossetti, A.O., Thesen, T., Wang, C., Devinsky, O., Kuzniecky, R., Doyle, W. \& Madsen, J.R. (2009). The human K-complex represents an isolated cortical down-state. Science, 324, 1084-1087. 
Cheyne, D., Bells, S., Ferrari, P., Gaetz, W. \& Bostan, A.C. (2008). Self-paced movements induce high-frequency gamma oscillations in primary motor cortex. NeuroImage, 42, 332-342. https://doi.org/10.1016/j.neuroimage.2008.04.178

Colrain, I.M., Crowley, K.E., Nicholas, C.L., Afifi, L., Baker, F.C., Padilla, M., Turlington, S.R. \& Trinder, J. (2010). Sleep evoked delta frequency responses show a linear decline in amplitude across the adult lifespan. Neurobiol. Aging, 31, 874-883. https://doi.org/10.1016/j.neurobiolaging.2008.06.003

Colrain, I.M., Turlington, S. \& Baker, F.C. (2009). Impact of Alcoholism on Sleep Architecture and EEG Power Spectra in Men and Women. Sleep, 32, 1341-1352.

Dijk, D.-J. (2008). Slow-wave sleep, diabetes, and the sympathetic nervous system. Proc. Natl. Acad. Sci, 105, $1107-1108$.

Eckhorn, R., Bauer, R., Jordan, W., Brosch, M., Kruse, W., Munk, M. \& Reitboeck, H.J. (1988). Coherent oscillations: A mechanism of feature linking in the visual cortex? Biol. Cybern, 60, 121-130. https://doi.org/10.1007/BF00202899

EEG Brain Signal Classification for Epileptic Seizure Disorder Detection. (2019). Elsevier. https://doi.org/10.1016/C2018-0-01888-5

Ehlers, C.L. \& Kupfer, D.J. (1997). Slow-wave sleep: do young adult men and women age differently? J. Sleep Res, 6, 211-215.

Engel, A.K., Kreiter, A.K., König, P. \& Singer, W. (1991). Synchronization of oscillatory neuronal responses between striate and extrastriate visual cortical areas of the cat. Proc. Natl. Acad. Sci. U. S. A, 88, 60486052.

Fellinger, R., Gruber, W., Zauner, A., Freunberger, R. \& Klimesch, W. (2012). Evoked traveling alpha waves predict visual-semantic categorization-speed. Neuroimage, 59-318, 3379-3388. https://doi.org/10.1016/j.neuroimage.2011.11.010

Fisher, S. (2014). Neurofeedback in the Treatment of Developmental Trauma: Calming the Fear-Driven Brain. W. W. Norton \& Company, New York.

Fitzgibbon, S.P., Lewis, T.W., Powers, D.M.W., Whitham, E.W., Willoughby, J.O. \& Pope, K.J. (2013). Surface Laplacian of central scalp electrical signals is insensitive to muscle contamination. IEEE Trans. Biomed. Eng, 60, 4-9. https://doi.org/10.1109/TBME.2012.2195662

Foster, J.J., Sutterer, D.W., Serences, J.T., Vogel, E.K. \& Awh, E. (2017). Alpha-Band Oscillations Enable Spatially and Temporally Resolved Tracking of Covert Spatial Attention. Psychol. Sci, 28, 929-941. https://doi.org/10.1177/0956797617699167

Freiwald, W.A., Kreiter, A.K. \& Singer, W. (1995). Stimulus dependent intercolumnar synchronization of single $\begin{array}{lllll}\text { unit responses in cat area } 17 . & \text { Neuroreport, } & 6, & 2348-2352 .\end{array}$ https://doi.org/10.1097/00001756-199511270-00018

Frien, A., Eckhorn, R., Bauer, R., Woelbern, T. \& Kehr, H. (1994). Stimulus-specific fast oscillations at zero phase between visual areas V1 and V2 of awake monkey. Neuroreport, 5, 2273-2277. https://doi.org/10.1097/00001756-199411000-00017

Galambos, R., Makeig, S. \& Talmachoff, P.J. (1981). A 40-Hz auditory potential recorded from the human scalp. Proc. Natl. Acad. Sci. U. S. A., 78, 2643-2647. https://doi.org/10.1073/pnas.78.4.2643

Gasser, T. \& Molinari, L. (1996). The analysis of the EEG. Stat. Methods Med. Res, 5, 67-99. https://doi.org/10.1177/096228029600500105

Gastaut, Hf. (1952). Etude electrocorticographique de la reactivite des rythmes rolandiques. Rev Neurol Paris, $87,176-182$.

Gastaut, H. (1952). Etude d'une activité électroencéphalographique méconnue: le rythme rolandique en arceau. Marseille Méd, 89, 296-310.

Gevins, A., Smith, M.E., McEvoy, L \& Yu, D. (1997). High-resolution EEG mapping of cortical activation related to working memory: effects of task difficulty, type of processing, and practice. Cereb. Cortex N. Y. N, 1991 7, 374-385. https://doi.org/10.1093/cercor/7.4.374 
Gilbertson, T., Lalo, E., Doyle, L., Di Lazzaro, V., Cioni, B. \& Brown, P. (2005). Existing motor state is favored at the expense of new movement during $13-35 \mathrm{~Hz}$ oscillatory synchrony in the human corticospinal system. J. Neurosci. Off. J. Soc. Neurosci, 25, 7771-7779. https://doi.org/10.1523/JNEUROSCI.1762-05.2005

Gordon, E., Palmer, D.M. \& Cooper, N. (2010). EEG alpha asymmetry in schizophrenia, depression, PTSD, panic disorder, ADHD and conduct disorder. Clin. EEG Neurosci, 41, 178-183.

Gray, C.M., König, P., Engel, A.K. \& Singer, W. (1989). Oscillatory responses in cat visual cortex exhibit inter-columnar synchronization which reflects global stimulus properties. Nature, 338, 334-337. https://doi.org/10.1038/338334a0

Grunwald, M., Weiss, T., Krause, W., Beyer, L., Rost, R., Gutberlet, I. \& Gertz, H.J. (1999). Power of theta waves in the EEG of human subjects increases during recall of haptic information. Neurosci. Lett, 260, 189-192. https://doi.org/10.1016/s0304-3940(98)00990-2

Hadjipapas, A., Adjamian, P., Swettenham, J.B., Holliday, I.E. \& Barnes, G.R. (2007). Stimuli of varying spatial scale induce gamma activity with distinct temporal characteristics in human visual cortex. NeuroImage, 35, 518-530. https://doi.org/10.1016/j.neuroimage.2007.01.002

Headley, D.B. \& Paré, D. (2017). Common oscillatory mechanisms across multiple memory systems. Npj Sci. Learn, 2, 1-8. https://doi.org/10.1038/s41539-016-0001-2

Herrero, M.-T., Barcia, C. \& Navarro, J. (2002). Functional anatomy of thalamus and basal ganglia. Childs Nerv. Syst, 18, 386-404. https://doi.org/10.1007/s00381-002-0604-1

Hobson, H.M. \& Bishop, D.V.M. (2017). The interpretation of mu suppression as an index of mirror neuron activity: past, present and future. $R$. Soc. Open Sci, 4, 160662. https://doi.org/10.1098/rsos.160662

Inui, K., Kawamoto, H., Kawakita, M., Wako, K., Nakashima, H., Kamihara, M. \& Nomura, J. (1994). Temporal Delta Wave and Ischemic Lesions on MRI. Psychiatry Clin. Neurosci, 48, 891-898. https://doi.org/10.1111/j.1440-1819.1994.tb03091.x

Ishihara, T. \& Yoshii, N. (1972). Multivariate analytic study of EEG and mental activity in Juvenile delinquents. Electroencephalogr. Clin. Neurophysiol, 33, 71-80. https://doi.org/10.1016/0013-4694(72)90026-0

Jasper, H.H. (1958). The ten-twenty electrode system of the International Federation. Electroencephalogr Clin Neurophysiol, 10, 370-375.

Jurcak, V., Tsuzuki, D. \& Dan, I. (2007). 10/20, 10/10, and 10/5 systems revisited: Their validity as relative head-surface-based positioning systems. NeuroImage, 34, 1600-1611. https://doi.org/10.1016/j.neuroimage.2006.09.024

Kaminska, A., Cheliout-Heraut, F., Eisermann, M., Touzery de Villepin, A. \& Lamblin, M.D. (2015). EEG in children, in the laboratory or at the patient's bedside. Neurophysiol. Clin. Clin. Neurophysiol, 45, 65-74. https://doi.org/10.1016/j.neucli.2014.11.008

Karbowski, K. (2002). Hans Berger (1873-1941). J. Neurol, 249, 1130-1131. https://doi.org/10.1007/s00415-002-0872-4

Kasteleijn-Nolst Trenité, D., Rubboli, G., Hirsch, E., Martins da Silva, A., Seri, S., Wilkins, A., Parra, J., Covanis, A., Elia, M., Capovilla, G., Stephani, U. \& Harding, G. (2012). Methodology of photic stimulation revisited: Updated European algorithm for visual stimulation in the EEG laboratory: Methodology of Photic Stimulation Revisited. Epilepsia, 53, 16-24. https://doi.org/10.1111/j.1528-1167.2011.03319.x

Kramis, R., Vanderwolf, C.H. \& Bland, B.H. (1975). Two types of hippocampal rhythmical slow activity in both the rabbit and the rat: relations to behavior and effects of atropine, diethyl ether, urethane, and pentobarbital. Exp. Neurol, 49, 58-85. https://doi.org/10.1016/0014-4886(75)90195-8

Kreiter, A.K. \& Singer, W. (1996). Stimulus-dependent synchronization of neuronal responses in the visual cortex of the awake macaque monkey. J. Neurosci. Off. J. Soc. Neurosci, 16, 2381-2396.

Kristeva, R., Patino, L. \& Omlor, W. (2007). Beta-range cortical motor spectral power and corticomuscular coherence as a mechanism for effective corticospinal interaction during steady-state motor output. NeuroImage, 36, 785-792. https://doi.org/10.1016/j.neuroimage.2007.03.025

Kropotov, J.D. (2016). Chapter 2.2 - Alpha Rhythms, Kropotov, J.D. (Ed.), Functional Neuromarkers for Psychiatry. Academic Press, San Diego, 89-105. https://doi.org/10.1016/B978-0-12-410513-3.00008-5 
Kropotov, J.D. (2009). Chapter 3 - Beta Rhythms, Kropotov, J.D. (Ed.), Quantitative EEG, Event-Related Potentials and Neurotherapy. Academic Press, San Diego, 59-76. https://doi.org/10.1016/B978-0-12-374512-5.00003-7

Kurahashi, H. \& Hirose, S. (1993). Autosomal Dominant Nocturnal Frontal Lobe Epilepsy, Adam, M.P., Ardinger, H.H., Pagon, R.A., Wallace, S.E., Bean, L.J., Stephens, K., Amemiya, A. (Eds.). GeneReviews ${ }^{\circledR}$. University of Washington, Seattle, Seattle (WA).

Kushida, C.A., Littner, M.R., Morgenthaler, T., Alessi, C.A., Bailey, D., Coleman, J., Friedman, L., Hirshkowitz, M., Kapen, S., Kramer, M., Lee-Chiong, T., Loube, D.L., Owens, J., Pancer, J.P. \& Wise, M. (2005). Practice parameters for the indications for polysomnography and related procedures: an update for 2005 . Sleep, 28, 499-521. https://doi.org/10.1093/sleep/28.4.499

Lalo, E., Gilbertson, T., Doyle, L., Di Lazzaro, V., Cioni, B. \& Brown, P. (2007). Phasic increases in cortical beta activity are associated with alterations in sensory processing in the human. Exp. Brain Res, 177, 137145. https://doi.org/10.1007/s00221-006-0655-8

Laporte, N., Sébire, G., Gillerot, Y., Guerrini, R. \& Ghariani, S. (2002). Cognitive epilepsy: ADHD related to focal EEG discharges. Pediatr. Neurol, 27, 307-311.

Larsen, S. (2012). The Neurofeedback Solution: How to Treat Autism, ADHD, Anxiety, Brain Injury, Stroke, PTSD, and More, Original. ed. edition. ed. Healing Arts Press, Rochester, Vt.

Lawley, A., Evans, S., Manfredonia, F. \& Cavanna, A.E. (2015). The role of outpatient ambulatory electroencephalography in the diagnosis and management of adults with epilepsy or nonepileptic attack disorder: A systematic literature review. Epilepsy Behav. EB, 53, 26-30. https://doi.org/10.1016/j.yebeh.2015.09.032

Lega, B.C., Jacobs, J. \& Kahana, M. (2012). Human hippocampal theta oscillations and the formation of episodic memories. Hippocampus, 22, 748-761. https://doi.org/10.1002/hipo.20937

Llinás, R. \& Ribary, U. (1993). Coherent 40-Hz oscillation characterizes dream state in humans. Proc. Natl. Acad. Sci. U. S. A., 90, 2078-2081. https://doi.org/10.1073/pnas.90.5.2078

Louis, E.K.S., Frey, L.C., Britton, J.W., Frey, L.C., Hopp, J.L., Korb, P., Koubeissi, M.Z., Lievens, W.E., Pestana-Knight, E.M. \& Louis, E.K.S. (2016a). Appendix 1. The Scientific Basis of EEG: Neurophysiology of EEG Generation in the Brain. American Epilepsy Society.

Louis, E.K.S., Frey, L.C., Britton, J.W., Frey, L.C., Hopp, J.L., Korb, P., Koubeissi, M.Z., Lievens, W.E., Pestana-Knight, E.M. \& Louis, E.K.S. (2016b). Introduction. American Epilepsy Society.

Maas, J.W. (1979). Neurotransmitters and depression Too much, too little, or too unstable? Trends Neurosci, 2, 306-308. https://doi.org/10.1016/0166-2236(79)90118-8

Magnus, O. \& Van der Holst, M. (1987). Zeta waves: a special type of slow delta waves. Electroencephalogr. Clin. Neurophysiol, 67, 140-146. https://doi.org/10.1016/0013-4694(87)90036-8

Malik, A.S. \& Amin, H.U. (2017). Chapter 1 - Designing an EEG Experiment, Malik, A.S., Amin, H.U. (Eds.). Designing EEG Experiments for Studying the Brain. Academic Press, 1-30. https://doi.org/10.1016/B978-0-12-811140-6.00001-1

Malmivuo, J. \& Plonsey, R. (1995). Bioelectromagnetism: principles and applications of bioelectric and biomagnetic fields. Oxford University Press, New York.

Marcuse, L.V., Fields, M.C. \& Yoo, J. (Jenna) (2016). 2 - The normal adult EEG, Marcuse, L.V., Fields, M.C., Yoo, J. (Jenna) (Eds.). Rowan's Primer of EEG (Second Edition). Elsevier, London, 39-66. https://doi.org/10.1016/B978-0-323-35387-8.00002-0

McAllister, C.J., Rönnqvist, K.C., Stanford, I.M., Woodhall, G.L., Furlong, P.L. \& Hall, S.D. (2013). Oscillatory Beta Activity Mediates Neuroplastic Effects of Motor Cortex Stimulation in Humans. J. Neurosci, 33, 7919-7927. https://doi.org/10.1523/JNEUROSCI.5624-12.2013

McEvoy, L.K., Pellouchoud, E., Smith, M.E. \& Gevins, A. (2001). Neurophysiological signals of working memory in normal aging. Brain Res. Cogn. Brain Res, 11, 363-376.

Mizuki, Y., Kajimura, N., Nishikori, S., Imaizumi, J. \& Yamada, M. (1984). Appearance of frontal midline theta rhythm and personality traits. Folia Psychiatr. Neurol. Jpn, 38, 451-458. 
Moretti, D.V., Paternicò, D., Binetti, G., Zanetti, O. \& Frisoni, G.B. (2013). EEG upper/low alpha frequency power ratio relates to temporo-parietal brain atrophy and memory performances in mild cognitive impairment. Front. Aging Neurosci, 5. https://doi.org/10.3389/fnagi.2013.00063

Moretti, D.V., Paternicò, D., Binetti, G., Zanetti, O. \& Frisoni, G.B. (2012). EEG markers are associated to gray matter changes in thalamus and basal ganglia in subjects with mild cognitive impairment. NeuroImage, 60 , 489-496. https://doi.org/10.1016/j.neuroimage.2011.11.086

Moretti, D.V., Prestia, A., Fracassi, C., Geroldi, C., Binetti, G., Rossini, P.M., Zanetti, O. \& Frisoni, G.B. (2011). Volumetric differences in mapped hippocampal regions correlate with increase of high alpha rhythm in Alzheimer's disease. Int. J. Alzheimers Dis, 2011, 208218. https://doi.org/10.4061/2011/208218

Murphy, M. \& Öngür, D. (2019). Decreased peak alpha frequency and impaired visual evoked potentials in first episode psychosis. NeuroImage Clin, 22. https://doi.org/10.1016/j.nicl.2019.101693

Muthukumaraswamy, S.D. \& Singh, K.D. (2008). Spatiotemporal frequency tuning of BOLD and gamma band MEG responses compared in primary visual cortex. NeuroImage, 40, 1552-1560. https://doi.org/10.1016/j.neuroimage.2008.01.052

Nambu, A. (2009). Basal Ganglia: Physiological Circuits, Squire, L.R. (Ed.). Encyclopedia of Neuroscience. Academic Press, Oxford, 111-117. https://doi.org/10.1016/B978-008045046-9.01298-5

Niedermeyer, E. (1997). Alpha rhythms as physiological and abnormal phenomena. Int. J. Psychophysiol. Off. J. Int. Organ. Psychophysiol, 26, 31-49. https://doi.org/10.1016/s0167-8760(97)00754-x

Oberman, L.M., Hubbard, E.M., McCleery, J.P., Altschuler, E.L., Ramachandran, V.S. \& Pineda, J.A. (2005). EEG evidence for mirror neuron dysfunction in autism spectrum disorders. Brain Res. Cogn. Brain Res, 24, 190-198. https://doi.org/10.1016/j.cogbrainres.2005.01.014

Ogawa, T., Sonoda, H., Suzuki, M., Ishiwa, S., Goto, K., Sawaguchi, H. \& Wakayama, K. (1989). Developmental characteristics of the alpha waves of EEG in normal healthy children. No Hattatsu Brain Dev, 21, 417-423.

Packard, M.G. (2001). Basal Ganglia, Smelser, N.J., Baltes, P.B. (Eds.). International Encyclopedia of the Social \& Behavioral Sciences. Pergamon, Oxford, 1044-1048. https://doi.org/10.1016/B0-08-043076-7/03463-X

Patrick, G.J. (1996). Improved neuronal regulation in ADHD: An application of 15 sessions of photic-driven EEG neurotherapy. J. Neurother, 1, 27-36.

Pilon, M., Zadra, A., Joncas, S. \& Montplaisir, J. (2006). Hypersynchronous delta waves and somnambulism: brain topography and effect of sleep deprivation. Sleep, 29, 77-84.

Pizzagalli, D., Pascual-Marqui, R.D., Nitschke, J.B., Oakes, T.R., Larson, C.L., Abercrombie, H.C., Schaefer, S.M., Koger, J.V., Benca, R.M. \& Davidson, R.J. (2001). Anterior cingulate activity as a predictor of degree of treatment response in major depression: evidence from brain electrical tomography analysis. Am. J. Psychiatry, 158, 405-415. https://doi.org/10.1176/appi.ajp.158.3.405

Quantitative EEG, Event-Related Potentials \& Neurotherapy. (2009). Elsevier. https://doi.org/10.1016/B978-0-12-374512-5.X0001-1

Quyen, M.L.V., Muller, L.E., Telenczuk, B., Halgren, E., Cash, S., Hatsopoulos, N.G., Dehghani, N. \& Destexhe, A. (2016). High-frequency oscillations in human and monkey neocortex during the wake-sleep cycle. Proc. Natl. Acad. Sci, 113, 9363-9368. https://doi.org/10.1073/pnas.1523583113

Regan, D. \& Spekreijse, H. (1986). Evoked potentials in vision research 1961-1986. Vision Res. Twenty-Fifth Anniversary, 26, 1461-1480. https://doi.org/10.1016/0042-6989(86)90168-9

Renzel, R., Baumann, C.R. \& Poryazova, R. (2016). EEG after sleep deprivation is a sensitive tool in the first diagnosis of idiopathic generalized but not focal epilepsy. Clin. Neurophysiol. Off. J. Int. Fed. Clin. Neurophysiol, 127, 209-213. https://doi.org/10.1016/j.clinph.2015.06.012

Ritter, P., Moosmann, M. \& Villringer, A. (2009). Rolandic alpha and beta EEG rhythms' strengths are inversely related to fMRI-BOLD signal in primary somatosensory and motor cortex. Hum. Brain Ma30, 1168-1187. https://doi.org/10.1002/hbm.20585

Robbins, J. (2008). A Symphony in the Brathe Evolution of the New Brain Wave Biofeedback, Revised, Expanded ed. edition. ed. Grove Press / Atlantic Monthly Press, New York. 
Sasaki, K., Tsujimoto, T., Nishikawa, S., Nishitani, N. \& Ishihara, T. (1996). Frontal mental theta wave recorded simultaneously with magnetoencephalography and electroencephalography. Neurosci. Res, 26, 79-81. https://doi.org/10.1016/0168-0102(96)01082-6

Sekimoto, M., Kato, M., Watanabe, T., Kajimura, N. \& Takahashi, K. (2011). Cortical regional differences of delta waves during all-night sleep in schizophrenia. Schizophr. Res, 126, 284-290. https://doi.org/10.1016/j.schres.2010.11.003

Seneviratne, U., Mohamed, A., Cook, M. \& D'Souza, W. (2013). The utility of ambulatory electroencephalography in routine clinical practice: a critical review. Epilepsy Res, 105, 1-12. https://doi.org/10.1016/j.eplepsyres.2013.02.004

Shafer, P.O., Buelow, J.M., Noe, K., Shinnar, R., Dewar, S., Levisohn, P.M., Dean, P., Ficker, D., Pugh, M.J. \& Barkley, G.L. (2012). A consensus-based approach to patient safety in epilepsy monitoring units: Recommendations for preferred practices. Epilepsy Behav, 25, 449-456. https://doi.org/10.1016/j.yebeh.2012.07.014

Smith, M.E., McEvoy, L.K. \& Gevins, A. (1999). Neurophysiological indices of strategy development and skill acquisition. Brain Res. Cogn. Brain Res, 7, 389-404.

Snyder, S.M., Quintana, H., Sexson, S.B., Knott, P., Haque, A.F.M. \& Reynolds, D.A. (2008). Blinded, multi-center validation of EEG and rating scales in identifying ADHD within a clinical sample. Psychiatry Res, 159, 346-358.

Swartwood, J.N., Swartwood, M.O., Lubar, J.F. \& Timmermann, D.L. (2003). EEG differences in ADHD-combined type during baseline and cognitive tasks. Pediatr. Neurol, 28, 199-204.

Swettenham, J.B., Muthukumaraswamy, S.D. \& Singh, K.D. (2009). Spectral properties of induced and evoked gamma oscillations in human early visual cortex to moving and stationary stimuli. J. Neurophysiol, 102, 1241-1253. https://doi.org/10.1152/jn.91044.2008

Tallon-Baudry, C. \& Bertrand, O. (1999). Oscillatory gamma activity in humans and its role in object representation. Trends Cogn. Sci, 3, 151-162. https://doi.org/10.1016/S1364-6613(99)01299-1

Teplan, M. (2002). Fundamentals of EEG measurement. Meas. Sci. Rev, 2, 1-11.

Tesche, C.D. \& Karhu, J. (2000). Theta oscillations index human hippocampal activation during a working memory task. Proc. Natl. Acad. Sci. U. S. A, 97, 919-924. https://doi.org/10.1073/pnas.97.2.919

Tononi, G. \& Cirelli, C. (2006). Sleep function and synaptic homeostasis. Sleep Med. Rev, 10, 49-62.

Tsujimoto, T., Shimazu, H. \& Isomura, Y. (2006). Direct Recording of Theta Oscillations in Primate Prefrontal and Anterior Cingulate Cortices. J. Neurophysiol, 95, 2987-3000. https://doi.org/10.1152/jn.00730.2005

Tyner, F.S. \& Knott, J.R. (1983). Fundamentals of EEG Technology: Basic concepts and methods. Lippincott Williams \& Wilkins.

Uhlhaas, P.J. \& Singer, W. (2006). Neural synchrony in brain disorders: relevance for cognitive dysfunctions and pathophysiology. Neuron, 52, 155-168. https://doi.org/10.1016/j.neuron.2006.09.020

Vanderwolf, C.H. (1969). Hippocampal electrical activity and voluntary movement in the rat. Electroencephalogr. Clin. Neurophysiol, 26, 407-418. https://doi.org/10.1016/0013-4694(69)90092-3

Vertes, R.P. (2005). Hippocampal theta rhythm: A tag for short-term memory. Hippocampus, 15, 923-935. https://doi.org/10.1002/hipo.20118

Walter, W.G. (1936). The location of cerebral tumours by electro-encephalography. The Lancet, 228, 305-308.

Watemberg, N., Alehan, F., Dabby, R., Lerman-Sagie, T., Pavot, P. \& Towne, A. (2002). Clinical and radiologic correlates of frontal intermittent rhythmic delta activity. J. Clin. Neurophysiol. Off. Publ. Am. Electroencephalogr. Soc, 19, 535-539.

Watkins, K.E. \& Jenkinson, N. (2016). Chapter 8 - The Anatomy of the Basal Ganglia, Hickok, G., Small, S.L. (Eds.). Neurobiology of Language. Academic Press, San Diego, 85-94. https://doi.org/10.1016/B978-0-12-407794-2.00008-0

Weber, A.B., Albert, D.V., Yin, H., Held, T.P. \& Patel, A.D. (2017). Diagnosis of Electrical Status Epilepticus During Slow-Wave Sleep With 100 Seconds of Sleep. J. Clin. Neurophysiol. Off. Publ. Am. Electroencephalogr. Soc, 34, 65-68. https://doi.org/10.1097/WNP.0000000000000307 
Werhahn, K.J. (2009). Epilepsy in the elderly. Dtsch. Arzteblatt Int, 106, 135-142. https://doi.org/10.3238/arztebl.2009.0135

Whitham, E.M., Lewis, T., Pope, K.J., Fitzgibbon, S.P., Clark, C.R., Loveless, S., DeLosAngeles, D., Wallace, A.K., Broberg, M. \& Willoughby, J.O. (2008). Thinking activates EMG in scalp electrical recordings. Clin. Neurophysiol. Off. J. Int. Fed. Clin. Neurophysiol, 119, 1166-1175. https://doi.org/10.1016/j.clinph.2008.01.024

Whitham, E.M., Pope, K.J., Fitzgibbon, S.P., Lewis, T., Clark, C.R., Loveless, S., Broberg, M., Wallace, A., DeLosAngeles, D., Lillie, P., Hardy, A., Fronsko, R., Pulbrook, A. \& Willoughby, J.O. (2007). Scalp electrical recording during paralysis: quantitative evidence that EEG frequencies above $20 \mathrm{~Hz}$ are contaminated by EMG. Clin. Neurophysiol. Off. J. Int. Fed. Clin. Neurophysiol, 118, 1877-1888. https://doi.org/10.1016/j.clinph.2007.04.027

Williams, J.H.G., Waiter, G.D., Gilchrist, A., Perrett, D.I., Murray, A.D. \& Whiten, A. (2006). Neural mechanisms of imitation and "mirror neuron" functioning in autistic spectrum disorder. Neuropsychologia, 44, 610-621. https://doi.org/10.1016/j.neuropsychologia.2005.06.010

Wirrell, E.C. (2010). Prognostic significance of interictal epileptiform discharges in newly diagnosed seizure disorders. J. Clin. Neurophysiol. Off. Publ. Am. Electroencephalogr. Soc, 27, 239-248. https://doi.org/10.1097/WNP.0b013e3181 ea4288

Yuval-Greenberg, S., Tomer, O., Keren, A.S., Nelken, I. \& Deouell, L.Y. (2008). Transient induced gamma-band response in EEG as a manifestation of miniature saccades. Neuron, 58, 429-441. https://doi.org/10.1016/j.neuron.2008.03.027

Zhang, Y., Chen, Y., Bressler, S.L. \& Ding, M. (2008). Response preparation and inhibition: The role of the cortical sensorimotor beta rhythm. Neuroscience, 156, 238-246. https://doi.org/10.1016/j.neuroscience.2008.06.061

\section{Copyrights}

Copyright for this article is retained by the author(s), with first publication rights granted to the journal.

This is an open-access article distributed under the terms and conditions of the Creative Commons Attribution license (http://creativecommons.org/licenses/by/3.0/). 